\title{
Bridging Space Over Time: Global Virtual Team Dynamics and Effectiveness
}

\author{
Martha L. Maznevski • Katherine M. Chudoba \\ McIntire School of Commerce, University of Virginia, Charlottesville, Virginia 22903-2493, martha@virginia.edu \\ College of Business, Florida State University, Tallahassee, Florida 32306-1110, kchudoba@cob.fsu.edu
}

$\mathrm{V}$ irtual teams comprise an important structural component of many organizations and are particularly important in globally dispersed enterprises. This article reports an intensive study of three global virtual teams within a single organization. Using adaptive structuration theory as a template for organizing and interpreting both qualitative and quantitative data, the authors offer an important view of how effective virtual teams operate. Effective global virtual teams fit their communication patterns to the task, and they generate a deep rhythm of face-to-face communications interspersed among periods of remote communication.

Daniel Robey

\begin{abstract}
Global virtual teams are internationally distributed groups of people with an organizational mandate to make or implement decisions with international components and implications. They are typically assigned tasks that are strategically important and highly complex. They rarely meet in person, conducting almost all of their interaction and decision making using communications technology. Although they play an increasingly important role in multinational organizations, little systematic is known about their dynamics or effectiveness. This study built a grounded theory of global virtual team processes and performance over time. We built a template based on Adaptive Structuration Theory (DeSanctis and Poole 1994) to guide our research, and we conducted a case study, observing three global virtual teams over a period of 21 months. Data were gathered using multiple methods, and qualitative methods were used to analyze them and generate a theory of global virtual team dynamics and effectiveness. First, we propose that effective global virtual team interaction comprises a series of communication incidents, each configured by aspects of the team's structural and process elements. Effective outcomes were associated with a fit among an interaction incident's form, decision process, and complexity. Second, effective global virtual teams sequence these incidents to generate a deep rhythm of regular face-toface incidents interspersed with less intensive, shorter incidents using various media. These two insights are discussed with respect to other literature and are elaborated upon in several propositions. Implications for research and practice are also outlined.
\end{abstract}

(Distributed Teams; Electronic Communication; Global Virtual Teams; Grounded Theory; Media Choice; Multicultural Teams; Temporal Rhythms)

In multinational organizations, global teams increasingly make and implement important decisions. Just as technology facilitated information transmission around the world, it now enables globally distributed people to collaborate on issues and challenges facing a company at the international level (Harasim 1993, Ives and Jarvenpaa 1991). These global virtual teams were almost unheard of a decade ago, but today they serve as a critical mechanism for integrating information, making decisions, and implementing actions around the world (Canney Davison and Ward 1999).

Global virtual teams are groups that (a) are identified by their organization(s) and members as a team; (b) are responsible for making and/or implementing decisions important to the organization's global strategy; (c) use technology-supported communication substantially more than face-to-face communication; and (d) work and live in different countries. Lipnack and Stamps (1997) define a virtual team as "a group of people who interact through 
interdependent tasks guided by common purpose" and work " across space, time, and organizational boundaries with links strengthened by webs of communication technologies." Some authors reserve the term "virtual" for teams that never meet face-to-face (Canney Davison and Ward 1999, Jarvenpaa et al. 1998, Kristof et al. 1995), but most refer to a virtual relationship as one that is at least mostly conducted over technology (Geber 1995, Melymuka 1997b, Townsend et al. 1996, Young 1998). Kristof et al. (1995) and Jarvenpaa and Leidner (1998) describe global virtual teams as culturally diverse and geographically dispersed. We add that global virtual teams are also global in their task. Global strategies integrate a company's resources, regions, and customer interfaces while maintaining local responsiveness where necessary (Bartlett and Ghoshal 1989, Ghoshal 1987, Kobrin 1991, Kogut 1985). Managers from around the world must build close networks and interact intensively to achieve a global strategy's potential, functions served well by global virtual teams (Adler 1997, Bartlett and Ghoshal 1989).

Empirical research on global virtual teams is limited to a few studies on specific elements of global virtual team process. Research on distributed teams' use of communications technology is much more prolific, and studies on team dynamics are almost ubiquitous. When this literature is applied to global virtual teams the implications are often equivocal or even conflicting. When added together, the simple conclusions from single studies do not provide a well-integrated understanding of global virtual team process and performance.

\section{Conceptual Background}

This section reviews the literatures on technology-supported distributed teams and multinational teams, then summarizes Adaptive Structuration Theory. It concludes by describing the research template that guided our study's data gathering and analysis.

\section{Technology-Supported Distributed Teams}

We reviewed all studies on technology-supported distributed teams published between 1990 and 1998 in 11 major journals publishing research on information systems, groups, and international business. ${ }^{1}$ As summarized in Table 1, we found 41 studies.

The most common theme in the controlled and quasiexperimental research compared face-to-face with technology configurations to mediate communication. In some studies face-to-face groups performed better than technology-mediated groups (e.g., Hightower and Sayeed 1996, Smith and Vanecek 1990); in others they performed worse (e.g., Ocker et al. 1995-1996, Straus 1996); in others there was no difference on quality-related outcomes (e.g., Farmer and Hyatt 1994, Valacich et al. 1993). Furthermore, these relationships changed and evolved over time (e.g., Hollingshead et al. 1993). Although task type was often proposed to moderate the relationship between a medium and its effect on performance (e.g., O'Connor et al. 1993), there did not seem to be a consistent pattern of task types for which communications technology was better or worse. Some studies concluded that a combination of media including face-to-face outperformed one without face-to-face (e.g., Ocker et al. 1998).

The few studies that crossed organizational or significant geographic boundaries found that these boundaries affected the context in which communication took place and the communication itself (e.g., Turoff et al. 1993). Internationally distributed teams were examined in only two studies, both focusing on the role of trust in global teams that never met in person (Jarvenpaa et al. 1998, Jarvenpaa and Leidner 1998). They found that trust, which was critical to the team's ability to manage decision processes, could be built swiftly; however, this trust was very fragile.

Multidimensional field studies examined technology use among members of a distributed organizational group over time. All demonstrated that context and time helped explain some of the relationships that appeared conflicting or equivocal when studied individually (e.g., Fulk 1993, Hiltz et al. 1991, Schmitz and Fulk 1991). For example, DeSanctis and Jackson (1994) showed that the benefits from using more complex communications technology increased as the task became more complex; Hinds and Kiesler (1995) observed that lateral and extradepartmental communication used telephone rather than e-mail or voicemail, increasing collaboration; and Zack (1993) found that the more shared a group's interpretive context was, the more members were able to communicate using seemingly less rich technologies.

Taken together, these studies suggest that a global virtual team's most effective use of communications technology will be shaped by dimensions of the team's task and its context, but they do not offer a great deal of specific guidance for research on these teams.

\section{Multinational Teams}

Research on multinational teams is far more limited than research on distributed teams, with most of it focusing on the role of cultural composition. Culture is the set of deeplevel values associated with societal effectiveness, shared by an identifiable group of people (Maznevski et al. 1997). Multicultural team effectiveness research usually compares the performance of culturally diverse groups 
Controlled, Not Field Context

Chidambaram and Jones 1993

Farmer and Hyatt 1994

Galegher and Kraut 1994

Hightower and Sayeed 1996

Hiltz, Johnson, and Turoff 1991

Hollingshead, McGrath, and O'Connor 1993

Ocker, Fjermestad, Hiltz, and Johnson 1998

Ocker, Hiltz, Turoff, and Fjermestad 1995-1996

O'Connor, Gruenfeld, and McGrath 1993

Smith and Vanecek $1990^{\circ}$

Straus 1996

Valacich, George, Nunamaker, and Vogel 1994

Valacich, Paranka, George, and Nunamaker 1993

Walther 1995

Weisband, Schneider, and Connolly 1995

$\begin{array}{cc}\text { No } & \text { No } \\ \text { No } & \text { No } \\ 2 \text { weeks } & \text { No } \\ \text { No } & \text { No } \\ \text { No } & \text { No } \\ 13 \text { weeks } & \text { No } \\ 2 \text { weeks } & \text { No } \\ \text { No } & \text { No } \\ 13 \text { weeks } & \text { No } \\ 2 \text { weeks } & \text { Location } \\ \text { No } & \text { No } \\ \text { No } & \text { No } \\ \text { No } & \text { No } \\ 5 \text { weeks } & \text { No } \\ \text { No } & \text { No } \\ & \\ \text { No } & \text { No }\end{array}$

Fulk 1993

1 wk, 4 wks

Jarvenpaa, Knoll, and Leidner $1998^{\mathrm{b}}$

Lind and Zmud 1995

Rice 1992

Schmitz and Fulk 1991

Trevino and Webster 1992

No

No

No

No

Ctries, Progs ${ }^{\mathrm{C}}$

No

No

No

Field In-depth or Case

Ahuja and Carley 1998

DeSanctis and Jackson 1994

4 months

Finholt and Sproull 1990

$2+$ years

3 days

Hinds and Kiesler 1995

Jarvenpaa and Leidner $1998^{\mathrm{b}}$

2 days

Lea, O'Shea, and Fung 1995

$1 \mathrm{wk}, 4 \mathrm{wks}$

Orlikowski and Yates 1994

4 years

2 years

Orlikowski, Yates, Okamura, and Fujimoto 1995

18 months

Schatz 1991-1992

$1+$ years

Varied

1 year

1 week

$\sim 1$ week

Universities

Divisions

No

No

Ctries, Progs ${ }^{c}$

Divisions

Organizations

No

Webster 1998

Zack 1993

Zack and McKenney 1995

Research labs

Org's, Loca'ns ${ }^{d}$

No

No

No

Other

Ching, Holsapple, and Whinston 1992 (Theory)

$N / A$

No

Jarvenpaa and Ives 1994 (Theory)

$N / A$

$N / A$

Divisions

Pickering and King 1995 (Theory)

$N / A$

Organizations

Spears and Lea 1994 (Theory)

$N / A$

No

N/A

No

Walther 1996 (Theory)

Walther, Anderson, and Park 1994 (Meta-analysis)

Varied

No

No

aAlthough Smith and Vanecek's 1990 study was conducted in the field, we categorized it as not being in a field context because the task, solving a hypothetical murder mystery, was not a realistic organizational decision-making task.

bThese two articles (Jarvenpaa, Knoll, and Leidner 1998 and Jarvenpaa and Leidner 1998) report on the same group research study; however, we classified them differently because Jarvenpaa et al. (1998) focused on a narrower set of quantified variables than did Jarvenpaa and Leidner (1998), which analyzed the content of communication among a subset of the groups.

${ }^{\mathrm{c} C o u n t r i e s}$ and University Programs.

dOrganizations and Geographic Locations. 
with that of culturally homogeneous groups, generally finding that multicultural groups offer high potential for performance on complex tasks but often fail to realize that potential (Adler 1997).

Cultural values influence the perceptual filter through which a person interprets information needed to make decisions (Adler 1997, Hofstede 1980). These differences in perspective offer potential for multicultural teams to perform well (e.g., Ling 1990, McLeod and Lobel 1992, Watson et al. 1993). However, cultural values also influence members' preferences for social interaction norms (Bettenhausen and Murnighan 1991, Earley 1993, Zander 1997). Because of this often hidden influence, multicultural groups find cooperative decision making difficult (e.g., Anderson 1983, Fiedler 1966, Kirchmeyer and Cohen 1992, Watson et al. 1993), hindering their performance. Two sets of empirical studies have shown that when multicultural groups engage in effective integration processes such as communication and conflict resolution, they perform at least as well as, and sometimes better than, homogeneous teams (Maznevski 1994a, Watson et al. 1993).

In summary, a global virtual team's cultural composition may be an influential structural characteristic, and integration processes are likely key to performance. These studies were all conducted in highly controlled settings in a single instance or over short periods of time, leaving many critical questions unanswered.

\section{Adaptive Structuration Theory and Global Virtual Teams}

Adaptive Structuration Theory (AST) is a high-level theory explaining the relationship between technology use and social interaction in creating group outcomes in organizational contexts (DeSanctis and Poole 1994). AST is based on structuration theory developed by Giddens $(1979,1984)$, which proposes that a complete understanding of social interaction requires incorporating explanations of both the structure of relationships and the dynamics or processes of relationships. The processes both take place in social structures, and shape those structures over time.

The heart of AST is the role of advanced information technology and its appropriation by members of the organization as they work together. The theory describes how a technology's inherent structural characteristics shape interaction patterns without determining the interaction in a definitive way. How people choose to appropriate the technology helps to shape their decision processes. A broad metapattern of social structure emerges in the group, influenced by use of the new technology. DeSanctis and Poole (1994) also suggest that analysis based on AST can identify certain patterns more likely associated with organizational effectiveness than others.

AST offers an ideal grounding for this study. Established theories of distributed teams and multinational teams focus on either technology or dynamics, or tend to limit themselves to a narrow context in space or time. Our interest is in examining technology and group dynamics across space and over time, and this high-level theory provides strong guidance for identifying and analyzing the appropriate patterns.

\section{Research Template}

We concluded from our literature review that a satisfactory explanation of global virtual team effectiveness must take into account multiple structural and process elements over time. These are precisely the research conditions that call for a qualitative, grounded theory study (Eisenhardt 1989). We also concluded that phenomena related to global virtual teams, such as distributed teams and multinational teams, have been studied sufficiently to provide a solid foundation, and that AST provides an appropriate conceptual model for this foundation. Therefore, we conducted a grounded theory field study using AST as a template (King 1998). We designed our study to capture the major categories and propositions of AST, and we conducted initial analyses within these assumptions. Table 2 shows the categories and subcategories we incorporated into the design of our study, based on their importance in previous research on distributed and/or multinational teams. We also expected that adjustments, insertions, and deletions to the template would ensue, based on our findings from the analyses.

\section{Method}

We studied three global virtual teams, collecting data over a period of 21 months: 9 months of intensive observation and collection, preceded by 3 months of informal discussions with the teams and their managers, and followed by 9 months of more discussions. We collected data using multiple methods, including interviews, observations, communication logs, questionnaires, and company documentation, and conducted qualitative analyses of these data both within each case and across cases. Our data collection protocol is summarized in Table 3.

\section{Site and Case Selection}

Our research was conducted at Manufacturing Technology Inc. (MTI), ${ }^{2}$ headquartered in the eastern United States, in cooperation with two of its strategic partners (both headquartered in Europe with global operations). MTI was a joint venture of a Fortune 100 company with an Asian corporation. It designed, manufactured, and sold industrial technology globally. By studying teams based in a single company, we held the structural characteristics of the company and its industry constant. In this setting 
Table 2 Template of Categories and Subcategories for Initial Research Design

\begin{tabular}{|c|c|c|c|}
\hline Structural Characteristics & Technology Appropriation & Decision Processes & Decision Outcomes \\
\hline $\begin{array}{l}\text { Technology } \\
\text { - Structural features } \\
\text { - Richness } \\
\text { - Social presence } \\
\text { - Need for recipient availability } \\
\text { - Accessibility } \\
\text { Organizational Environment } \\
\text { - Organizational culture } \\
\text { - Structure } \\
\text { Task } \\
\text { - Strategic scope and importance } \\
\text { - Ambiguity } \\
\text { - Complexity } \\
\text { Group Characteristics } \\
\text { - Member distribution } \\
\text { - Member background: } \\
\text { culture, profession } \\
\text { - Group size } \\
\text { - Stage of development }\end{array}$ & $\begin{array}{l}\text { Media Choice } \\
\text { Appropriation Moves } \\
\text { - Directly use structures } \\
\text { - Relate structures to other } \\
\text { structures } \\
\text { - Constrain or interpret the } \\
\text { structures as they are } \\
\text { used } \\
\text { - Make judgements about the } \\
\text { structures } \\
\text { Instrumental Uses } \\
\text { - Functions of interpersonal } \\
\text { interaction } \\
\text { - Task activities } \\
\text { - Exercise power or influence } \\
\text { Attitudes towards Use } \\
\text { - Confidence } \\
\text { - Value } \\
\text { - Challenge/ motivation }\end{array}$ & $\begin{array}{l}\text { Generate } \\
\text { - Planning tasks } \\
\text { - Creativity tasks } \\
\text { Choose } \\
\text { - Intellective tasks } \\
\text { - Preference or decision } \\
\text { making } \\
\text { Negotiate } \\
\text { - Cognitive conflict } \\
\text { - Mixed-motive } \\
\text { Execute } \\
\text { Communicate } \\
\text { Participate }\end{array}$ & $\begin{array}{l}\text { Quality } \\
\text { - As perceived by team members } \\
\text { - As evaluated by manager team } \\
\text { reports to } \\
\text { - As evaluated by other recipients } \\
\text { of the output } \\
\text { Commitment } \\
\text { - Individual agreement with team } \\
\text { decisions } \\
\text { - Willingness to carry out team } \\
\text { decisions } \\
\text { Cohesion } \\
\text { - Strength of relationships in } \\
\text { the group } \\
\text { - Cohesion around task versus } \\
\text { relationships } \\
\text { Individual Satisfaction }\end{array}$ \\
\hline
\end{tabular}

Note: Main categories (column headings) from Adaptive Structuration Theory (DeSanctis and Poole 1994). Subcategories suggested by previous research.

we were able to observe teams in various stages of development, with cooperation from management. Furthermore, the multiple strategic alliances allowed us to examine global virtual team dynamics across multiple types of boundary-spanning (e.g., country, culture, company).

Using a theoretical replication logic with multiple cases (Yin 1989), senior MTI managers helped us identify global virtual teams to study, agreeing to provide access to three teams that fit our criteria. We sought teams that differed maximally on three structural characteristics suggested by the literature review: task, composition, and length of time working together. The three teams we studied were MakeTech, implementing a co-development and coselling agreement with a strategic alliance partner; SellTech, implementing a volume sales contract and partnership with MTI's largest customer; and NewTech, charged with integrating MTI's three divisions to create a new product for a new global market. The partner companies also agreed to participate in the study.

All of the teams had multiple levels of membership, including a core that made and was responsible for implementing the decisions and peripheral members who supported the team. We defined the core members as "the global virtual team," and they became the main focus of our research. Each project we studied was only one aspect of each team member's work.

\section{Data Collection}

We collected data from multiple sources at several points in time, guided by a protocol developed according to recommendations of qualitative research and grounded theory (e.g., Eisenhardt 1989, King 1998, Miles and Huberman 1994, Strauss and Corbin 1990, Yin 1989). We described and assessed each team's structural characteristics, technology use, group processes, and group outcomes, including the subcategories identified in our conceptual analysis. We gathered data on other aspects of global virtual team functioning to capture other important elements and to assess the validity of our initial expectations. Our protocol incorporated examining the relationships among these elements, and data collection at several points in time. Although the protocol guided our data collection, we adapted the details as our interactions with the teams unfolded.

We collected data using multiple methods over the 21 months. Each method added richness and depth to a specific part of the model, and we studied each element in the template using multiple methods. We conducted semistructured interviews with senior team members, 
Table 3

Data Collection Strategy

\begin{tabular}{|c|c|c|c|c|c|c|c|c|}
\hline \multirow[b]{2}{*}{ Data Source } & \multicolumn{4}{|c|}{ Focal Category } & \multicolumn{4}{|c|}{ Team } \\
\hline & SC & TA & $\mathrm{DP}$ & DO & $\begin{array}{l}\text { MTI (Overall } \\
\text { Information) }\end{array}$ & $\begin{array}{c}\text { MakeTech } \\
\text { (8 members) }\end{array}$ & $\begin{array}{c}\text { NewTech } \\
\text { (12 members) }\end{array}$ & $\begin{array}{c}\text { SellTech } \\
\text { (9 members) }\end{array}$ \\
\hline $\begin{array}{l}\text { Semi-structured } \\
\text { interview- } \\
\text { around team }\end{array}$ & $\checkmark$ & & & $\checkmark$ & $\begin{array}{l}\text { - } 20 \text { individuals, } 4 \\
\text { interviewed } 2+ \\
\text { times } \\
\text { - } \text { average length } 60 \\
\text { min }\end{array}$ & $\begin{array}{l}\text { - } 2 \text { individuals, } 2 \text { times } \\
\text { each } \\
\text { - } \text { average length } 60 \\
\text { min }\end{array}$ & $\begin{array}{l}\text { - } 2 \text { individuals, } 3 \text { times } \\
\text { each } \\
\text { - } \text { average length } 45 \\
\text { min }\end{array}$ & $\begin{array}{l}\text { - } 2 \text { individuals, } 2 \text { times } \\
\text { each } \\
\text { - average length } 60 \\
\text { min }\end{array}$ \\
\hline $\begin{array}{l}\text { Semi-structured } \\
\text { interview-within } \\
\text { team }\end{array}$ & & $\sqrt{ }$ & $\checkmark$ & $\checkmark$ & & $\begin{array}{l}\text { - } 4 \text { members } \\
\text { - average length } 60 \\
\text { min }\end{array}$ & $\begin{array}{l}\text { - } 2 \text { members } \\
\text { - average length } 60 \\
\text { min }\end{array}$ & $\begin{array}{l}\text { - } 3 \text { members } \\
\text { - average length } 60 \\
\text { min }\end{array}$ \\
\hline $\begin{array}{l}\text { Unstructured } \\
\text { Interview }\end{array}$ & $\sqrt{ }$ & $\checkmark$ & $\checkmark$ & $\checkmark$ & & $\begin{array}{l}\text { - at least } 1 \text { with each } \\
\text { member, up to } 5 \text { with } \\
\text { most members } \\
\text { - average length } 20 \\
\text { min }\end{array}$ & $\begin{array}{l}\text { - } 5 \text { members, } 3 \text { with } \\
\text { one member } \\
\text { - average length } 20 \\
\text { min }\end{array}$ & $\begin{array}{l}\text { - at least } 1 \text { with } 9 \\
\text { members, up to } 3 \\
\text { with most members } \\
\text { - average length } 20 \\
\text { min }\end{array}$ \\
\hline $\begin{array}{l}\text { Observation of } \\
\text { face-to-face } \\
\text { meeting }\end{array}$ & $\sqrt{ }$ & $\sqrt{ }$ & $\checkmark$ & $\sqrt{ }$ & & $\begin{array}{l}\text { - two 2-day meetings, } \\
\text { half of a third 2-day } \\
\text { meeting, all breaks, } \\
\text { demonstrations, and } \\
\text { meals during } \\
\text { meeting } \\
\text { - total } 45 \text { hours } \\
\text { observation }\end{array}$ & $\begin{array}{l}\text { - no face-to-face } \\
\text { meetings scheduled } \\
\text { during data } \\
\text { collection period } \\
\text { - no face-to-face } \\
\text { meetings of whole } \\
\text { group held during } \\
\text { collection period }\end{array}$ & $\begin{array}{l}\text { - one 2-day meeting, } \\
\text { half of a second 2- } \\
\text { day meeting, all } \\
\text { breaks, } \\
\text { demonstrations, and } \\
\text { meals during } \\
\text { meeting } \\
\text { - total } 25 \text { hours } \\
\text { observation }\end{array}$ \\
\hline $\begin{array}{l}\text { Observation of } \\
\text { conference call }\end{array}$ & $\checkmark$ & $\checkmark$ & $\sqrt{ }$ & & & - none & - none & $\begin{array}{l}\text { - } 7 \text { conference calls, } \\
\text { monthly on first } \\
\text { Thurs of month } \\
\text { - average length } 60 \\
\text { min }\end{array}$ \\
\hline $\begin{array}{l}\text { Communication } \\
\text { logs }\end{array}$ & & $\sqrt{ }$ & $\checkmark$ & $\sqrt{ }$ & & - 7 members returned & - 7 members returned & - 8 members returned \\
\hline Questionnaires & $\checkmark$ & $\checkmark$ & $\sqrt{ }$ & $\sqrt{ }$ & & - 8 members returned & - 7 members returned & - 8 members returned \\
\hline $\begin{array}{l}\text { Company } \\
\text { documentation }\end{array}$ & $\checkmark$ & & & $\checkmark$ & $\begin{array}{l}\text { - vision statements } \\
\text { - reports } \\
\text { - product information } \\
\text { - company memos }\end{array}$ & $\begin{array}{l}\text { - agenda, minutes, } \\
\text { reports }\end{array}$ & $\begin{array}{l}\text { - product information, } \\
\text { sales strategies, } \\
\text { reports }\end{array}$ & $\begin{array}{l}\text { - agenda, minutes, } \\
\text { reports } \\
\text { - product information } \\
\text { from partner } \\
\text { company }\end{array}$ \\
\hline
\end{tabular}

Note: SC = structural characteristics; TA = technology appropriation; DP = decision procesesses; DO = decision outcomes.

managers to whom the teams reported, and key personnel who worked with the team to provide information on structural characteristics and group outcomes. We conducted semistructured and frequent unstructured interviews with team members to gain further details and perspective on all four elements and to explore in-depth the relationship among elements and dynamics over time.
Observations of face-to-face meetings and conference calls provided data concerning technology use, group processes, and the relationship among the elements and changes over time.

Because the companies would not permit recording, special care was taken to obtain valid data. Both researchers were present for almost all interviews and meetings. 
In the interviews, one researcher focused on asking questions and guiding the interview while the other took extensive notes that were reviewed by both researchers for completeness. In the meetings, both researchers took as many notes as possible, and compared notes and added comments for clarification and completeness immediately after. These notes were also compared with the meeting's agenda and minutes. Only one researcher was able to observe the conference calls. Extensive notes were taken, and these notes were reviewed by the other researcher, who asked questions and recorded comments for clarification. This technique was also used for the few interviews and meetings for which only one researcher was present.

Communication logs and questionnaires provided additional assessments of technology use, group processes, and some structural characteristics and group outcomes. These were limited to one point in time, but stimulated discussion with team members concerning how the variables changed over time. The questionnaires assessed each member's cultural orientation (Maznevski et al. 1997) and provided self-assessments of group process, outcome variables (Maznevski and DiStefano 1995), and technology use. The communication logs were conducted during a week the team identified as typical. During that week members recorded each voice mail, phone conversation, and face-to-face meeting made or received concerning the team's business, identifying whether the occurrence was scheduled or unscheduled, and summarizing the content. In addition, we asked members to provide us with copies of any faxes, letters, and e-mails about the team and its task sent or received during the week.

Finally, we also gathered MTI documentation concerning the teams and their mandates, including company vision and values statements, periodic reports, product information, meeting agendas and minutes, ongoing lists of action items, and blanket communications to all members of MTI.

\section{Data Analysis}

Although data collection and analysis are presented in two sections here because they represent different conceptual stages of the research process, chronologically the two activities overlapped (Eisenhardt 1989, Strauss and Corbin 1990). For example, early interviews and observations guided our development and presentation of the communication logs and questionnaires, and our analysis of these and earlier meetings guided what we looked for in later meetings and interviews. We conducted three types of data analysis: template coding (King 1998), axial coding (Strauss and Corbin 1990), and an analysis of emergent higher level relationships (Eisenhardt 1989, Yin
1989). We conducted these analyses within each case separately, then compared the analyses across cases to build a grounded theory of global virtual team dynamics. After conducting an initial pass of all analyses, we presented our description of each team to its members and incorporated their feedback into a final analysis of the teams.

Our initial data analyses followed template analysis coding procedures (King 1998). In contrast to a pure grounded theory approach, which begins with open coding (the coding of data without a priori idea of what the categories should be; Strauss and Corbin 1990), template analysis begins with coding according to the research template. Categories may be added, deleted, or shifted in their hierarchical level based on findings in the data. For example, we found that "degree of interdependence required" seemed to be a critical aspect of the task's characteristic on its own rather than being a subcategory of "complexity" as we had previously thought, so we raised it in the hierarchy. Our objective was to identify a single set of categories (eventually, theoretical constructs) that described all three teams' dynamics.

Both researchers coded the material separately, then compared analyses. As recommended by King (1998), we stopped coding when we agreed on all higher-order coding and most lower-order coding. For example, one team member stated to another on a conference call:

Why don't you e-mail me the spreadsheet with that action item, and once I see the part number and history details I'll be able to follow up and resolve the problem for you. ${ }^{3}$

We coded this item in four ways: technology appropriation-media choice-conference call; technology appropriation-media choice-e-mail; decision processes-communication; and decision processes-conflict resolutionproblem solving. In its context, the item provided us with important information on all four of these categories.

Although template coding is designed for use on textual data, we also applied it to the results of the questionnaires. Rather than analyzing the questionnaire results as samples indicative of a larger population, we looked at them as summarized information provided by individuals about themselves and their own team (Eisenhardt 1989, Miles and Huberman 1994, Strauss and Corbin 1990). We examined individual scores and patterns of scores within the group, group means on the scale, and variance within each group. The information coded from the questionnaires was used alongside the textual data as input to the next stage of analysis.

Following template coding, we conducted axial coding (Strauss and Corbin 1990) to achieve our theory generation objective. We again analyzed the data, this time to 
uncover relationships among categories and subcategories. We began with our conceptual template guiding our search for patterns, but we also looked for information that would disconfirm or add to our initial expectations. Some evidence about relationships was evident in direct statements from participants. Other information about relationships came from identifying patterns of categories that seemed to co-occur or to cause one another (Cook and Campbell 1979). We then checked these relationships for consistency across data gathered using different methods. Table 4 shows the final set of categories and subcategories that emerged from our analysis. ${ }^{4}$

Once we had captured the general relationships among concepts in the four main categories within and across cases, we looked for larger patterns and patterns over time. We looked for changes, adaptations, and evolutions, and tried to discern patterns associated with global virtual team effectiveness. We discussed what we had seen throughout our experiences with the teams and reinterviewed the senior managers involved with the teams, focusing especially on patterns across teams and time. Our final analysis objective was to generate a more parsimonious theory by identifying the categories and subcategories of variables that affected these global virtual teams the most, and articulating the ways in which they combined to affect decision outcomes.

\section{Results}

\section{MTI Overview}

MTI was one of the top producers of technological manufacturing equipment in North America. Its major product lines used standardized technology, and a new product line was planned to move the company into both new products and markets. The company had originally focused on the North American market, but in the 1990s the company began aggressively pursuing a global strategy. MTI, its partner companies, and its competitors assessed that it was becoming a strong global competitor.

MTI's organizational culture focused on speed, relationships, and quality. The company's human resource practices rewarded flexibility and teamwork, quality, and taking action quickly. The organization was structured by product group to ensure quick response to customers, with a very flat hierarchy to encourage strong relationships and fast decisions.

All MTI employees had access to a wide range of communications technology, including videoconferencing, teleconferencing, telephone, voice mail, electronic mail (email), fax, and paper mail. The employees differentiated these technologies on the four characteristics of richness, social presence, need for recipient availability, and medium accessibility (Straub and Karahanna 1998). Although videoconferencing was available, no one had used it in the previous year and none did while we were conducting our study, reportedly because it was not spontaneous enough nor was the quality high enough.

\section{MakeTech}

The MakeTech team was inaugurated three years prior to our study to manage a strategic alliance with a competitor headquartered in France. The companies codeveloped products using components from each company and had cross-selling agreements. The team decided specifications and logistics, and its members were responsible for contract implementation.

MakeTech's task had a high level of complexity and required a high level of interdependence. Each aspect of product development required input from both companies' engineers, approval for sale by both companies' managers, and certification under several sets of standards. Both companies' products required extensive engineering service after sales, so the cross-selling arrangements were also complex, with high interdependence. For example, "a problem with a customer's equipment could arise anywhere in the world at any time, and we might have to fix it using engineers from both companies at the same time."

The team was led by a senior manager from MTI. Six of the eight members were from MTI, and two from the partner company; all had engineering training. Of the MTI members, three were from headquarters, and three were from Western Europe (France, England, and Benelux). The two partner members were from France and England. Three MakeTech members did not speak English fluently.

The team was characterized by moderate cultural diversity. Members differed strongly in assumptions about whether primary responsibility should be to one's self or to the group; they differed moderately in whether their preferred task approach was careful planning or quick action. There was strong agreement to balance systems integration with an attitude of change and control.

The team's social interaction was structured around regular two-day face-to-face coordination meetings with very structured and full agendas, attended by all members. These meetings were initially held every two months, after a year they occurred every three months, and by the time we concluded our data collection they occurred every four months. The meetings accomplished several purposes. They allowed synchronous dialogue among all members, with a very fluid structure and intense interaction. Miscommunication from the past was 


\section{Table 4 Final Template of Categories and Subcategories Emerging from Data Analysis}

Category and

Subcategories

Definition

Structural Characteristics: Structural elements that shape the group's processes.

Technology

Accessibility

Richness

Social presence

Recipient availability

Task

Required interdependence

Complexity

Organization

Organizational Culture

Organizational Structure

Group

Boundaries spanned

Member background

Member context technology.
Media Choice

Instrumental Uses

Which of available media chosen to
convey a given message
Which decision process technology is
used for

clarified, major decisions were made, and implementation details worked out. Most importantly, team members said, they developed strong relationships. They went to special luncheons and dinners and held multiple breaks with meetings of various subgroups.
Table 4 Continued

\begin{tabular}{|c|c|}
\hline $\begin{array}{l}\text { Category and } \\
\text { Subcategories }\end{array}$ & Definition \\
\hline \multicolumn{2}{|c|}{$\begin{array}{l}\text { Decision Processes: Hierarchy of processes, each higher process } \\
\text { incorporates and requires all processes below to be carried out } \\
\text { effectively. }\end{array}$} \\
\hline Information gathering & $\begin{array}{l}\text { Retrieving and passing on unequivocal } \\
\text { data }\end{array}$ \\
\hline Problem solving & $\begin{array}{l}\text { Resolving minor issues and conflicts } \\
\text { related to the task }\end{array}$ \\
\hline Idea construction & $\begin{array}{l}\text { Generating new solutions and ideas to } \\
\text { contribute to the task, working on } \\
\text { these ideas to build them }\end{array}$ \\
\hline $\begin{array}{l}\text { Comprehensive } \\
\text { decision making }\end{array}$ & $\begin{array}{l}\text { Making major decisions about important } \\
\text { aspects of the task (contrasted with } \\
\text { Problem Solving) }\end{array}$ \\
\hline $\begin{array}{c}\text { Generating major } \\
\text { commitment }\end{array}$ & $\begin{array}{l}\text { Obtaining commitment from members } \\
\text { to implement the comprehensive } \\
\text { decisions }\end{array}$ \\
\hline \multicolumn{2}{|c|}{ Decision Outcomes: Consequences of decision processes. } \\
\hline Decision Quality & $\begin{array}{l}\text { Extent to which decision made meets or } \\
\text { exceeds expectations of team } \\
\text { members, senior managers, and other } \\
\text { stakeholders }\end{array}$ \\
\hline Action Quality & $\begin{array}{l}\text { Extent to which resulting implementation } \\
\text { meets or exceeds expectations of } \\
\text { team members, senior managers, and } \\
\text { other stakeholders }\end{array}$ \\
\hline $\begin{array}{l}\text { Commitment to } \\
\text { Team and } \\
\text { Decisions }\end{array}$ & $\begin{array}{l}\text { Extent to which team members are } \\
\text { committed to team and the decisions } \\
\text { it makes }\end{array}$ \\
\hline Cohesion & $\begin{array}{l}\text { Extent to which team members enjoy } \\
\text { working together and would like to } \\
\text { continue to work together }\end{array}$ \\
\hline
\end{tabular}

Between these meetings members interacted frequently: on average more than twice per day and, over a week, with at least five other team members. This communication mostly followed up on decisions made at the previous meeting or gathered information in anticipation of the next meeting. Team members cooperated in attending immediately to customer or development problems that arose. Their first preference of media was for telephone and second for e-mail or fax. Not all members had reliable access to e-mail, and some preferred not to use it except for transmitting very simple information. They held conference calls to resolve more complex problems that arose, usually with four to six hours of lead time.

MakeTech's decision outcomes were mixed. According to executives from MTI, the contract had not yet 
performed up to either company's expectations, and the project was behind schedule until near the end of our data collection. However, this was the first such agreement either company had engaged in, and it had been much more challenging than they had anticipated. Members and senior managers felt that getting this far was a great accomplishment. Product development quality was high and customer response was good. Both companies were enthusiastic about the future and lessons learned from this project, and were entering into other agreements using this team as a model. Members and senior managers from both companies consistently rated this team as effective. Team members themselves were strongly committed to the team and its decisions and demonstrated high cohesion:

This project has had a lot of struggles. Sometimes we're behind and they have the upper hand, sometimes they're behind and we have the upper hand. But we're all learning, and we're getting better, and we've had enough success in a very tough market that we intend to just keep going.

\section{NewTech}

NewTech was formed as we began our study. Its mission was to combine technologies from MTI's two product lines and develop and sell a new product for an emerging market. Both the product and the market were forecast to be the future of the industry. High-performing individuals were assigned to the team, all of whom were simultaneously selling or developing main components of the new product.

NewTech's task required a very high degree of interdependence and was very complex. The product technology and potential market characteristics were uncertain, and forecasts changed constantly. New software and hardware had to be developed, but it was uncertain which aspects of past technologies could be adapted and which had to be new. NewTech was to sort out all the equivocal information and create something profitable.

There were 12 members of the core NewTech team, all of whom were in MTI. Of the 6 members from headquarters, 2 were from marketing, 1 was a sales engineer, and 3 were product development engineers. Two members were from other U.S. cities (1 marketer and 1 sales engineer). Two product development engineers were located in East Asia, and two sales engineers were located in Benelux. One of the headquarters marketing members led the team. Unfortunately, none of the non-United States members responded to our correspondence, although we contacted them several times through multiple media.

Among the United States members, there were some unexpected cultural differences. There was an extreme bipolarity in assumptions about responsibility, with half the members believing that responsibility should be toward one's self first, and the other half believing that responsibility should be toward the group first. The group had more homogeneity in terms of task, with a dominant pattern of defining the task as changing and controlling and approaching it with action without excessive planning.

U.S. team members interacted frequently using all available media except conference calls and videoconferencing. There were no regular meetings for this project, although most of the U.S. members interacted during a regular biweekly sales meeting. During our data collection period there were no scheduled face-to-face meetings, but different subsets of headquarters team members often met spontaneously for one to two hours or more to discuss the project. Most of the issues the team addressed involved current products, their sales, and their adaptation for current customer needs in the new product area. The team leader sent occasional e-mails to the team asking for feedback on strategic issues. The only contact that we know of between U.S. members and non-U.S. members regarding this project was the inclusion of non-U.S. members on distribution lists of blanket information (to which they did not reply). Although most headquarters team members thought group processes were effective, the nonheadquarters personnel and one headquarters member did not rate the group's processes as effective. We surmised that the non-U.S. members would not have rated the communication quality as high.

During our data collection period and for several months afterwards, senior managers and executives expressed optimism about NewTech's performance: "We have our best people on that team, and we know they'll get us the right answers." After this time, executives became more vague: 'Yes, they're still working on it, and I think they're getting somewhere.' Just over a year after our formal data collection period, senior managers confirmed that the team had been disbanded. They reported, "The product turned out to be harder to get at than we thought, and we're going at it another way now."

\section{SellTech}

SellTech started meeting in the early 1990 s to manage an alliance between MTI and its largest customer, a global producer of industrial equipment. The agreement had two parts: a volume sales contract guaranty and a commitment to cooperative development for future product design. The contract was initially managed by an MTI sales engineer in England, but for the first 18 months those involved met only sporadically, and the customer was dissatisfied. The sales engineer could not get commitments 
from engineers and developers at MTI headquarters because he was not senior enough and was not present enough to build alternate relationships with them. About 18 months before our data collection began, a headquarters senior manager was assigned to head SellTech-the same one who led MakeTech. He began holding more regular meetings with required attendance and held members responsible for outcomes.

SellTech's main task, servicing the volume sales agreement, required a moderate degree of interdependence and was of moderate complexity. The partner company explained its requirements, MTI engineers provided their solutions, partner engineers tested those solutions on their own equipment and went back to MTI engineers with further questions, and so on in a sequential way. The customer's requirements were fairly stable and predictable, although sometimes challenging. SellTech's secondary task required a greater degree of interdependence and was of greater complexity. To achieve future codevelopment, team members from both companies shared future plans, including highly confidential product development innovations. Each helped the other adapt the plans and move into production, while ensuring that the new products would fit with the rest of their own product lines.

There were nine members of the core SellTech team. Of the four from MTI, two were from headquarters, one was from England, and one was from Scandinavia. Of the five from the partner firm, four were from the Northern European headquarters, and one was from the United States. All team members spoke English either as their first language or a fluent second language. Although the senior MTI manager officially led the team, partner members took a strong role in guiding it and sometimes overstepped the leader. In spite of the country differences, there was remarkable cultural homogeneity in this team. There was strong agreement that one's primary responsibility should be to the group, and also that goals should incorporate changing and controlling elements. In assumptions about task processes, most people preferred planning carefully before acting, but a few preferred moving directly to action.

SellTech's social interaction was structured around two streams of regular meetings. The whole team met monthly by conference call for about an hour to manage the details of the selling agreement. They followed up on commitments, tracked tests and deliveries, and resolved minor problems. They also met every four months for a two-day coordination meeting at MTI headquarters, with a very dense and structured agenda. This meeting's main purpose was to manage the future development of the contract by sharing plans and information, generating ideas about codevelopment, and building strong relationships through social meals and breaks.

Between these meetings, SellTech members conducted the team's work with other members of their respective organizations, contacting each other only when necessary. Each member interacted with the others less than once per day, and interacted with one or two other team members over a typical week. Their strongly preferred mode of communication was face-to-face because of the richness; however, they saw telephone as an acceptable substitute over distance. E-mail and fax were used almost exclusively to transmit agendas, specific requests, and factual information in response to a request. They planned on transmitting more information over e-mail, such as price lists and action schedules, once their various systems were more compatible.

SellTech was considered an unqualified success. Sales were at $150 \%$ of the guaranteed volume, codevelopment had proceeded with good results for about a year, and both companies had replicated this model with other customers and suppliers. Members were committed to their team and its decisions and had very strong cohesion. As one of the partner members said,

\footnotetext{
We were worried two years ago. We don't like to back out of commitments, and we didn't think we'd made the wrong choice. But we wondered what more we could do to make things happen. Since then things have turned around 180 degrees. This is our best supplier relationship.
}

\section{Toward a Theory of Global Virtual Team Dynamics and Effectiveness}

We developed two sets of insights from our analysis, each integrating structural and process elements affected by technological and social influences. First, we saw global virtual team dynamics as a series of interaction incidents. Each incident incorporates a set of decision processes using a particular medium and is shaped by a limited set of structural characteristics. Although there are infinite potential structure-process configurations, the number associated with effective interaction seems to be limited. Second, in effective global virtual teams the interaction incidents themselves are sequenced in a repeating temporal pattern. This basic pattern is defined by regular faceto-face meetings in which the intensity of interaction is extremely high, followed by a period of some weeks in which interaction incidents are less intense. Moreover, the decision process is organized to match this temporal pattern, rather than the other way around. In sum, within interaction incidents the medium and form are selected to match the function, but across incidents over time, the function is modified to match the medium and form. 
The most important performance dimensions to MTI were decision quality, action and implementation quality, member commitment to the team and its decisions, and cohesion among team members. These dimensions are consistent with those focused on by other organizational teams (e.g., Hackman 1990). We concluded that two of our three teams, MakeTech and SellTech, could be considered effective, with SellTech the more effective. Members and executives were satisfied with their decisions and actions. Team members rated their processes as effective and reported high commitment to the team and high team cohesion, concurring with our observations and analysis. We concluded that NewTech, on the other hand, was not an effective global virtual team. The team did not make decisions about the new product and did not take action to develop the product well. Most members who responded did not rate their processes or cohesion highly, and we did not observe them communicating among the group as a whole. NewTech's lack of effectiveness was a negative outcome for MTI, but it aided our analysis by providing a case of theoretical replication on the performance variable.

To generate theoretical insights from this analysis, we focused on similarities between MakeTech and SellTech and differences between them and NewTech, identifying variables and relationships that affected outcomes. We then sought evidence from previous literature to explain and validate our analysis. The following section describes each empirically generated insight, discusses related literature, then offers specific theoretical propositions concerning effective global virtual teams.

\section{Interaction Incidents}

Incident Process and Structure. Global virtual team interaction over time was best described as a series of social interaction incidents, or continuous communication among two or more members using one medium. Incidents varied on three important dimensions: decision process, message complexity, and form. In effective incidents, form was a function of decision process and message complexity.

Incidents' objectives fell within a hierarchy of four decision processes: information gathering, problem solving, idea generating, and comprehensive decision making. A fifth decision process, generating commitment to action, crossed this hierarchy and could be addressed at any point (see Table 4). Incidents also varied in message complexity, ranging from simple, single-dimensional messages to complex, multidimensional messages. Finally, incidents varied on two aspects of form: the medium selected and the incident's duration. In the effective teams, function influenced form: The higher the level of decision process and/or the more complex the message, the more rich the communication medium used and the longer the incident's duration.

We observed this pattern across MakeTech and SellTech's incidents. Members of these teams gathered simple information with quick e-mails, faxes, and phone calls, and solved problems using longer phone calls and conference calls. The two-day face-to-face coordination meetings were used for generating ideas and making comprehensive decisions. Incidents that served multiple purposes inherently had more dimensions and therefore higher complexity, and e-mail and fax were rarely used for incidents of multiple functions.

For example, one series of incidents began with a SellTech partner member requesting part specifications over e-mail (information gathering, simple message). This member then phoned an MTI member to reply that the specifications did not match his requirements (information gathering, generating commitment, moderately complex message). During the next conference call, the team decided to adapt the existing part with a temporary solution (problem solving, generating commitment, moderately complex message). Over the next few weeks, members from both companies shared information over phone, e-mail, and fax about different aspects of the product's design and manufacture (additional information gathering, varying levels of complexity), and in the subsequent conference call they discussed altering the product design to better fit the partner's requirements and also to become more attractive for other customers (generating ideas, generating commitment, complex message). MTI members redesigned the part, then phoned partner members with the new specifications, following up with fax (additional information gathering, complex message). During a third conference call, the partner placed a large order for the parts, and everyone discussed delivery and implementation arrangements (comprehensive decision making, generating commitment, complex message).

In NewTech, on the other hand, there was no clear relationship between incident form and function or complexity. At times the team attempted to discuss complex strategic issues over brief e-mails, and some headquarters members held lengthy face-to-face meetings to gather relatively simple information from each other. The team ended up with a great deal of information but no clear priorities or plans.

Our finding that effective global virtual team dynamics are characterized by a limited set of communication incident configurations echoes research by Orlikowski and Yates (1994, Yates and Orlikowski 1992), proposing genres-socially recognized categories of communication actions typified by form and substance-as a basic unit 
of communication in organizations. We observed a genre repertoire in the effective teams that included the coordination meeting, the regular scheduled conference call (SellTech), and the impromptu conference call. The communication between meetings was commonly identified by team members as "the day-to-day stuff" and may have represented a more loosely defined genre. We could not observe these genres evolving the way Orlikowski and Yates did; however, our finding that the effective teams' genre repertoire was circumscribed by a limited set of relationships between substance and form may illuminate a way of maintaining consistency and continued meaning among the genres of an effective organization's repertoire.

The hierarchy of decision processes that emerged from our observations closely follows the four categories of McGrath's (1984) typology of group tasks: generate, choose, negotiate, and execute. Like most organizational groups, these teams' tasks incorporated multiple types of decision processes (McGrath 1984, Turoff et al. 1993); however, the hierarchical arrangement of the processes is important to understanding global virtual team dynamics. The teams did not simply have different types of subtasks, but subtasks were linked together to build toward a comprehensive solution and set of actions, requiring consistency of communication and iterations of revisiting issues over time.

Our observations regarding media choice were consistent with the basic premise of media richness theory. Media are rich to the extent that they provide communication along multiple channels simultaneously (Ngwenyama and Lee 1997), and the more complex, equivocal, or uncertain a message, the richer the medium required to carry it effectively (Saunders and Jones 1990, Straub and Karahanna 1998). However, as in recent media choice studies (e.g., Dennis and Kinney 1998), we did not find a close one-to-one correspondence between message characteristics and media choice. Recent research emphasizes the role of social context and processes in choosing media (e.g., Ngwenyama and Lee 1997, Straub and Karahanna 1998). We found that the seemingly inconsistent matches between medium and message could be explained by structural characteristics, as discussed next.

These patterns in the process and structure of incidents can be described by the following four propositions:

PROPOSITION 1: In effective global virtual teams, the higher the level of decision process served by an incident, the more rich the medium appropriated and the longer the incident's duration.

PROPOSITION 2: In effective global virtual teams, the more complex the message content of an incident, the more rich the medium appropriated and the longer the incident's duration.

PROPOSITION 3. In effective global virtual teams, if a rich medium is not required, the most accessible medium will be used.

PROPOSITION 4: In effective global virtual teams, if an incident serves multiple functions or messages, its medium and duration will be shaped by the highest function and the most complexity.

Structural Characteristics and Incidents. The team's structural characteristics affected incidents' function and form. In the effective teams, a task with higher interdependence and/or greater complexity was associated with more frequent incidents, higher decision processes, and more complexity. For example, MakeTech's task required higher interdependence and was more complex than SellTech's primary task. MakeTech members engaged in more incidents with each other at all process levels than SellTech members did, and MakeTech's messages tended to be more complex. Of SellTech's messages, the more complex ones concerned future development rather than selling. NewTech's task required the highest level of interdependence and was the most complex, but members did not initiate as many task-related incidents as the other teams did.

Previous research on interdependence and complexity also reflects these observations. Thompson's (1967) typology of interdependence moves from pooled (individuals complete work independently and aggregate it) to sequential (work moves in a fixed sequence from one person or department to the next) to reciprocal (work moves back and forth among people or departments). Thompson and others (e.g., Lawrence and Lorsch 1967, Mintzberg 1989) demonstrated that higher levels of interdependence require more complex modes of organization, with reciprocal interdependence requiring frequent interaction among organizational members. Turoff et al. (1993) showed that the more interdependence required by a task, the more interaction the communications technology must support. Athanassiou and Nigh (1999) reported that in top management teams of multinational corporations, team members communicated more with each other about managing internationally as the interdependence among units of the company increased to achieve global integration.

We propose:

PROPOSITION 5A: In effective global virtual teams, the higher the task's required level of interdependence, the more communication incidents will be initiated.

PROPOSITION 5в: In effective global virtual teams, the 
more complex the task, the more complex the incidents' messages will be.

The structural characteristics of the group itself affected the complexity of the message and had a secondary influence on the incident's form. First, message complexity increased with the number of borders spanned by team members, and the effective teams used richer media when crossing boundaries. MakeTech and SellTech spanned company and locational boundaries by explaining messages thoroughly without using company-specific jargon or other shortcuts that we saw in NewTech messages. Members asked clarification questions frequently and responded to such questions carefully, behaviors we rarely saw in NewTech team incidents. Both MakeTech and SellTech deliberately addressed relationship building to develop shared views and trust across all types of boundaries, whereas NewTech did not attempt to build relationships across boundaries. These boundary-spanning activities were more frequent and more intense in MakeTech, which had more and greater boundaries.

In addition, cultural or professional differences among members increased message complexity on corresponding dimensions. For example, MakeTech's greatest cultural diversity concerned assumptions about responsibility, making issues of responsibility more complex. This team almost always used telephone or face-to-face conversation to address responsibility issues. The team had relative homogeneity regarding how the task should be defined, and often sent information to initiate a task in brief fax or e-mail messages. SellTech, on the other hand, had strong homogeneity on assumptions about responsibility, and contrary to MakeTech their communications regularly assigned responsibility over fax or e-mail or in quick phone calls. SellTech's greater cultural diversity centered around thinking a task through first versus taking action quickly, and the team usually addressed how to fix problems during longer phone or conference calls.

The team's structural characteristics also had a secondary but important effect on an incident's form. If the process and complexity of a message left room for choice of media, then final choice was determined by receiver preference and context in both MakeTech and SellTech; however, we saw no evidence that NewTech members tried to accommodate these characteristics.

These patterns are supported by research demonstrating how social context shapes media choice (Lee 1994, Markus 1994, Ngwenyama and Lee 1997, Saunders and Jones 1990). Particularly important is the finding that boundaryspanning increases message complexity. Within a single organization, location, culture, or profession, certain basic assumptions and information are shared (Schein 1984,
Zack 1993), reducing the number of required dimensions in a message. Messages that cross boundaries are inherently more complex, but can be made simpler if members build a shared view of their task and strong, trusting relationships among each other (Maznevski 1994b), as we saw in these teams.

In summary, we propose that:

PROPOSITION 6A: In effective global virtual teams, the greater the organizational and geographic boundaries spanned by a global virtual team's members, and the greater the cultural and professional differences among team members, the more complex the team's messages will be.

PROPOSITION 6B: In effective global virtual teams, the stronger the shared view and relationships among global virtual team members, the less complex the team's messages will be.

PROPOSITION 6C: Other things being equal, in effective global virtual teams the receiving member's preferences and context determines an incident's medium.

These six propositions, summarized in Figure 1, describe how social interaction creates decision outcomes in global virtual teams.

\section{Temporal Rhythms}

While our first insight focused on global virtual team dynamics as a series of more or less effective interaction incidents, the second one highlighted patterns across time. Effective teams were distinguished by a strong, repeating temporal pattern (Figure 2). In both MakeTech and SellTech, the basic rhythm was set by face-to-face coordination meetings. These meetings were extremely intense, with an agenda full of complex demonstrations, resolution of previous ambiguities, idea generation, comprehensive decision making, commitment generation, and relationship building. Interaction between coordination meetings was mainly in response to the previous meeting or in anticipation of the next one. The coordination meeting served as a heartbeat, rhythmically pumping new life into the team's processes before members circulated to different parts of the world and task, returning again at a predictable pace. These beats were spaced closer together in time if the task required greater interdependence and group members did not work together as easily, and further apart with less required interdependence and stronger group relationships. In SellTech a secondary rhythm was maintained with monthly one hour conference calls focused on current issues. Consistent with the propositions offered earlier, these meetings focused on mid-range decision processes and issues of moderate complexity and 
Figure 1 Individual Interaction Incidents in Global Virtual Teams

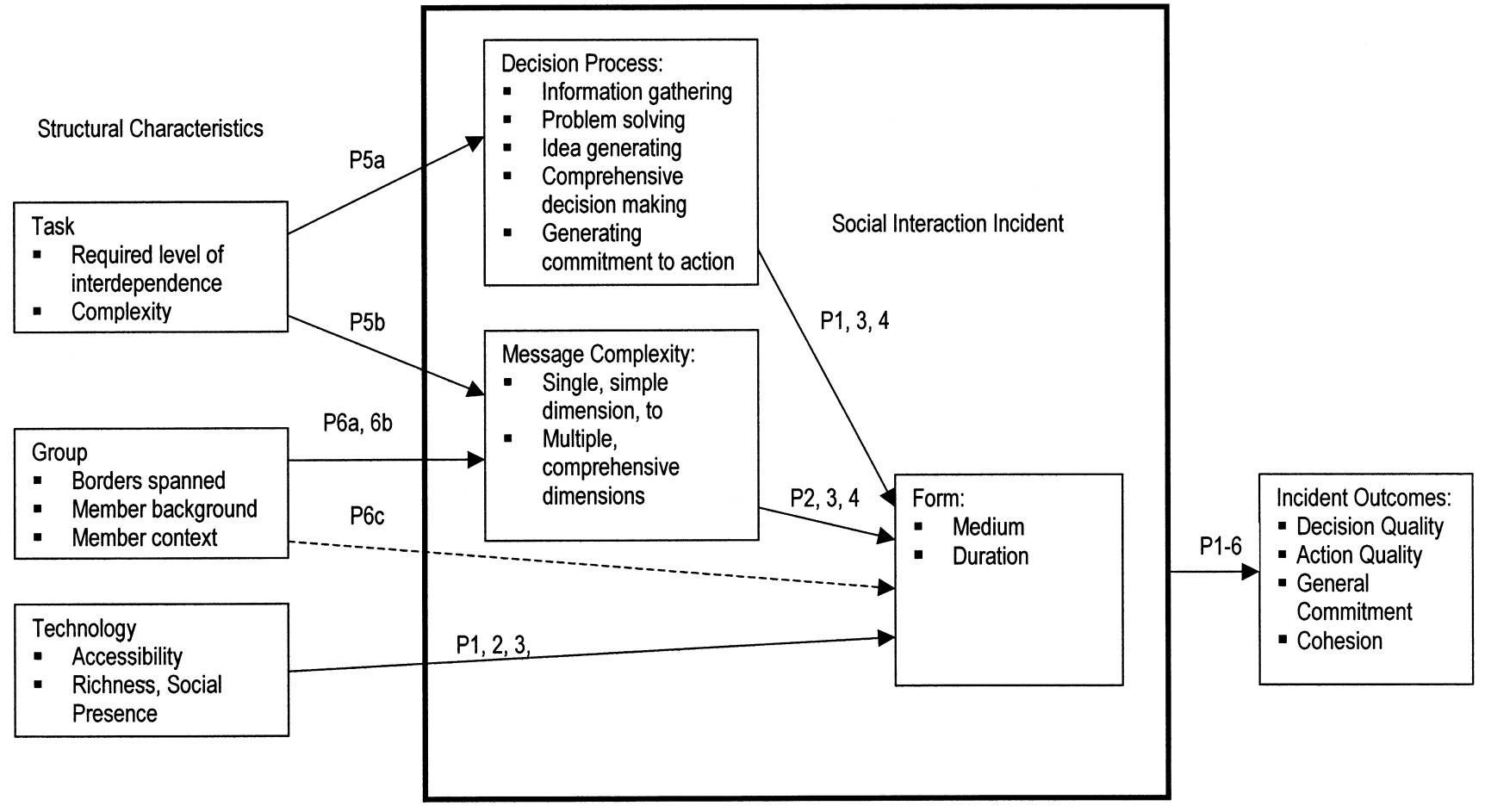

maintained continuous commitment to the sales contract. During conference calls there was an explicit recognition of the importance the coordination meetings played in structuring the overall team processes.

In both MakeTech and SellTech, this rhythm seemed to be as critical to effectiveness as the incidents themselves. While the individual coordination meetings helped in decision making and relationship building, the rhythm of meetings over time provided continuity and long-term stability. They reduced ambiguity in the task by structuring expectations and making response times predictable. It was this sense of rhythm that enabled members to work efficiently and confidently alone or in ever-changing subgroups between coordination meetings.

These patterns are hinted at in previous research but not developed fully. Orlikowski and Yates' study on the evolution of genres in an electronic community also shows potential temporal rhythms, although the authors do not analyze it in this way (Orlikowski and Yates 1994, Figure 6, p. 565). Both O'Hara-Devereux and Johansen (1994) and Canney Davison and Ward (1999) describe the importance of a rhythm in the team's interaction, but both describe a norm of continuous communication rather than the deeper patterns we observed.

Graphically, the patterns we observed appear very similar to those that Gersick $(1988,1989,1994)$ found in teams and in a venture capital organization. However, in Gersick's model $(1988,1989,1991)$, the periods of intense activity are transition points in a stream of punctuated equilibrium. They switch the team's (or organization's) mode of operating, and they occur when they do because of awareness of time or event rhythms. The interaction preceding a period of transition has a different deep structure than the interaction following it. In the global virtual teams we observed, the regular meetings defined the deep structure itself. Rather than a response to pacing, they functioned as a pulse. If a transition in operating modes occurred, it was discussed and negotiated during a coordination meeting (consistent with the complexity of the issue and level of decision process), but it was not always initiated there, nor was the coordination meeting's date altered to suit such transitions. The time lapse between coordination meetings was not determined by temporal or event pacing but by the task's complexity and required level of interdependence and by how effectively members could communicate over distance.

In many respects, the rhythms of our effective global virtual teams more closely echoed Gersick's venture capital firm (1994), in which the pacing patterns were strongly rhythmic. Brown and Eisenhardt (1997, 1998) also saw this pattern in their analysis of strategy in the high-technology industry. In their research, the firms that 


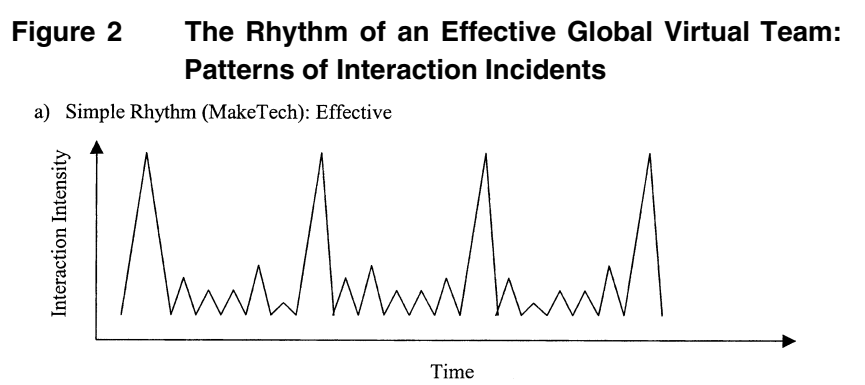

b) Dual Rhythm (SellTech): Effective

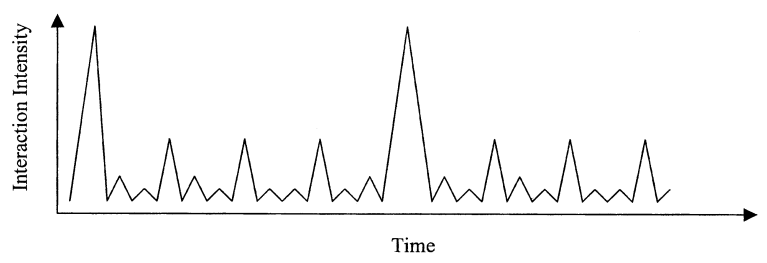

c) No Rhythm (NewTech): Ineffective

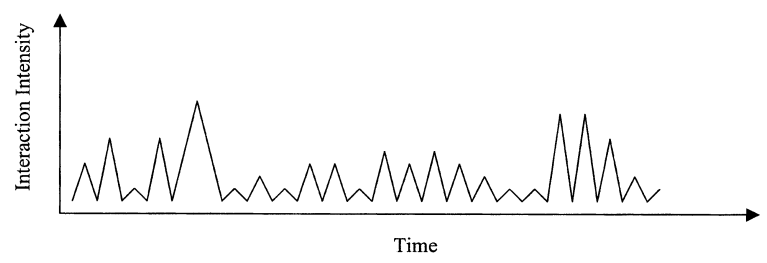

were most successful were those that engaged in strict time pacing or governing their strategic transitions with deliberate rhythms based on time. Like our teams, the rhythm drove the action rather than the other way around. And parallel to our discussion, Brown and Eisenhardt demonstrated that finding, or entraining, the right rhythm was critical to the strategy's effectiveness.

However, even in Brown and Eisenhardt's companies, the incidents defining the rhythm represented transitions, this time in a company's strategy. How well a company managed the transition was critical to capturing the benefits of rhythmic activity. Almost the opposite was true for our teams: The rhythm of meetings did not revolve around changes in interaction or direction but around reinforcement of ongoing relationships and current routines and views. The rhythm prevented inadvertent transitions from happening and maintained effective interaction equilibrium patterns.

The pattern of punctuated equilibria observed by these researchers seems highly robust; therefore, it is important to explore why the origin and functions of the rhythm in global virtual teams seem to be different. As AST would predict, the two-part explanation we offer is grounded in the relationship among structural characteristics, technology appropriation, and social interaction (DeSanctis and Poole 1994). First, like firms in volatile industries, global virtual teams must schedule rhythms rather than allow them to emerge spontaneously. In global virtual teams, the constraint is logistical rather than strategic. Because of their geographic distribution, these teams can rarely arrange to meet in a month, let alone next week or tomorrow.

Second, a scheduled rhythm should be structured around the most difficult performance challenge for the entity involved. The most difficult challenge for firms in volatile industries is managing change, and the best firms schedule these changes rhythmically. The most difficult challenge for these global virtual teams was managing social interaction and relationships, and the best teams scheduled interaction and relationship building rhythmically. Because effective teams matched an incident's function and complexity to its form, teams used the faceto-face rhythm-setting events to conduct their highest decision processes and communicate their most complex messages, regardless of the timing of transition points.

SellTech's conference calls suggest that the rhythm need not be defined entirely by face-to-face meetings. Various authors have described or predicted team effectiveness without the members ever meeting in person (e.g., Canney Davison and Ward 1999, Jarvenpaa and Leidner 1998, Lipnack and Stamps 1997). Our teams never took advantage of videoconferencing or even advanced electronic groupware that might have enriched some of their non-face-to-face interactions, so we cannot offer any firmly grounded propositions on this issue. However, we speculate that conducting regular meetings in person is essential to global virtual team effectiveness to the extent that the task requires a high degree of interdependence and there are geographic, organizational, and/ or cultural boundaries that must be spanned. For a task that requires compiling and aggregating unambiguous data from several sites in the same company and making linear decisions based on the aggregated data, faceto-face meetings may not be necessary. For the types of tasks and team compositions that characterized MakeTech and SellTech, the face-to-face medium seemed essential.

We also suggest that the frequency of these defining meetings can be decreased under certain conditions. In SellTech, the task was clear enough to members and there was enough homogeneity within the team that conference calls accomplished much of the business a face-to-face meeting might have. This allowed the team to hold faceto-face meetings with lower frequency than MakeTech could. An effective global virtual team may only hold full 
face-to-face meetings once a year as long as members have and continue to develop a highly shared view of their task, strong relationships and commitment to the team, and hold regular meetings using media of moderate richness throughout the year to develop a secondary rhythm.

Based on this discussion, we propose that:

PROPOSITION 7: Effective global virtual teams develop a rhythmic temporal pattern of interaction incidents, with the rhythm being defined by regular intensive face-to-face meetings devoted to higher level decision processes, complex messages, and relationship building.

\section{Conclusions}

This study developed a theory of global virtual team dynamics and effectiveness, grounded both in previous literature and in a qualitative, longitudinal field study. We proposed that effective global virtual team outcomes are a function of appropriate interaction incidents and the structuring of those incidents into a temporal rhythm. Within the structure of the technology available, effective interaction incidents match form to function and complexity, which are in turn affected by task and group characteristics. The temporal rhythm is structured by a defining beat of regular, intense face-to-face meetings, followed by less intensive, shorter interaction incidents using various media. We speculated that the length of time required between the face-to-face meetings depends on the level of interdependence required by the task and the degree of shared view and strength of relationships among members.

\section{Contributions to Research}

This study makes several contributions to organizational research. Most obviously, it provides a set of solidly grounded propositions for the further study of global virtual teams. Researchers can adapt these general propositions to specific teams and organizations. The propositions' internal validity should be assessed in more settings, and their generalizability should be evaluated by extending them to other types of tasks, teams, and technology.

In addition, the study clearly demonstrates the value of the approach advocated by DeSanctis and Poole (1994) beyond the GDSS setting used to illustrate AST. Understanding global virtual team effectiveness required a complete description of process and structure, of technology and social systems, and of the interaction among these dimensions over time. Theory development concerning other organizational phenomena would likely benefit from this approach.
We found that member background and context affected preferences and requirements for media choice, both directly and through their influence on incident complexity. Although research has shown that culture influences information systems use (Straub 1994), and that cross-national teams have difficulty generating trust (Jarvenpaa and Leidner 1998), our matching of specific types of cultural differences with particular aspects of global virtual team process adds a strong contribution. However, our sample characteristics did not allow us to make any broad generalizations concerning which other background and context dimensions would affect processes most and when. This is certainly an avenue for future research.

Finally, this research also suggests some future directions for group and organizational research. The temporal pattern observed here bore a strong resemblance to temporal pacing in teams (Gersick 1988, 1989) and in firms in the high-technology industry (Brown and Eisenhardt 1997, 1998; Gersick 1994); however, the rhythm's function in global virtual teams was quite different. The fact that several streams of research have separately uncovered very strong rhythms of interaction over time underscores the importance of the phenomenon. With similarities in temporal patterns but important differences in function, these findings may contribute to more general research on rhythmic patterns.

\section{Contributions to Practice}

The research also makes important contributions to global virtual team practice. We concur with the common recommendation in the practitioner-oriented literature that a virtual team meet face-to-face early in its existence (e.g., Canney Davison and Ward 1999, Carmel 1999, Melymuka 1997a, Merrick 1996). Moreover, we would add the importance of meetings' defining a rhythm to structure processes and expectations over time. Although more evidence is needed, it seems that the importance of the rhythm cannot be overstated.

The propositions here also provide some clear advice to team members concerning how to choose media between face-to-face meetings, identifying the important decision criteria. For example, if we had been able to tell the NewTech team with some certainty that their media selections were inconsistent with their task and group characteristics, and that the inconsistency would lead to poor outcomes, they may have switched their modes of interacting and made more progress on their task.

Global virtual teams are assigned some of the most important tasks in the organization. These teams were made possible by information technology, and future 
technological developments will only make their numbers and importance increase. Given this trend, it is essential that management researchers develop a strong understanding of global virtual team performance. This study represents an important step toward that explanation. Its grounding in both previous literature and empirical analysis and its focus on the relationship between structure and process enabled us to capture patterns in the complexity of global virtual team interaction over time and shed light on broader organizational issues. As organizational research focuses increasingly on more complex phenomena, this approach may help illuminate other areas as well.

\section{Acknowledgments}

The authors gratefully acknowledge financial support from McIntire School of Commerce and the cooperation of MTI and its business partners. They also appreciate insightful feedback from Gerry DeSanctis, Barb Haley, Adelaide King, Dan Robey, Peter Todd, Ellen Whitener, and three anonymous reviewers. Different aspects of this research have been presented at the 1996 International Conference on Information Systems in Cleveland, Ohio, and at the 1997 Academy of Management meeting in Boston, Massachusetts.

\section{Endnotes}

${ }^{1}$ The journals we reviewed were Academy of Management Journal, Academy of Management Review, Administrative Science Quarterly, Communications Research, Information Systems Research, Journal of Computer-Mediated Communication, Journal of Management Information Systems, Journal of International Business Studies, Management Information Systems Quarterly, Organization Science, and Small Group Research.

${ }^{2} \mathrm{At}$ the request of the participating company, all names are pseudonyms to maintain confidentiality. No other information has been disguised.

${ }^{3}$ Quotations are from our field notes. We listened carefully and wrote as closely to verbatim as possible. The quotations used to illustrate our data analysis were typical across situations and people. The teams reviewed our data reports and judged them to be accurate.

${ }^{4}$ Tables showing categorization of data are available from the authors.

\section{References}

Adler, N. J. 1997. International Dimensions of Organizational Behavior. South-Western College Publishing, Cincinnati, $\mathrm{OH}$.

Ahuja, M. K., K. M. Carley. 1998. Network structure in virtual organizations. J. Computer Mediated Comm. 3(4) 〈http://jcmc.huji. ac.il/vol3/issue4/ahuja.html $>$.

Anderson, L. R. 1983. Managing of the mixed-cultural work group. Organ. Behavior and Human Performance 31(3) 303-330.

Athanassiou, N., D. Nigh. 1999. The impact of U.S. company internationalization on top management team advice networks: A tacit knowledge perspective. Strategic Management J. 20(1) 83-92.

Bartlett, C. A., S. Ghoshal. 1989. Managing Across Borders: The Transnational Solution. Harvard Business School Press, Boston, MA.

Bettenhausen, K. L., J. K. Murnighan. 1991. The development and stability of norms in groups facing interpersonal and structural challenge. Admin. Sci. Quart. 36(1) 20-35.

Brown, S. L., K. M. Eisenhardt. 1997. The art of continuous change: Linking complexity theory and time-paced evolution in relentlessly shifting organizations. Admin. Sci. Quart. 42(1) 1-34.

- -1998 . Competing on the Edge: Strategy as Structured Chaos. Harvard Business School Press, Boston, MA.

Canney Davison, S., K. Ward. 1999. Leading International Teams. McGraw-Hill International, Berkshire, England.

Carmel, E. 1999. Global Software Teams: Collaborating Across Borders and Time Zones. Prentice-Hall, Upper Saddle River, NJ.

Chidambaram, L., B. Jones. 1993. Impact of communication medium and computer support on group perceptions and performance: A comparison of face-to-face and dispersed meetings. MIS Quart. 17(4) 465-516.

Ching, C., C. W. Holsapple, A. B. Whinston. 1992. Reputation, learning, and coordination in distributed decision-making contexts. $\mathrm{Or}$ gan. Sci. 3(2) 275-297.

Cook, T. D., D. T. Campbell. 1979. Quasi-experimentation: Design and Analysis Issues for Field Settings. Rand McNally, Chicago, IL.

Dennis, A. R., S. T. Kinney. 1998. Testing media richness theory in the new media: The effects of cues, feedback, and task equivocality. Inform. Systems Res. 9(3) 256-274.

DeSanctis, G., B. M. Jackson. 1994. Coordination of information technology management: Team-based structures and computer-based communication systems. J. Management Inform. Systems 10(4) $85-110$.

- M. S. Poole. 1994. Capturing the complexity in advanced technology use: Adaptive structuration theory. Organ. Sci. 5(2) 121147.

Earley, P. C. 1993. East meets west meets mideast: Further explorations of collectivistic and individualistic work groups. Acad. Management J. 36(2) 319-348.

Eisenhardt, K. M. 1989. Building theories from case study research. Acad. Management Rev. 14(4) 532-550.

Farmer, S. M., C. W. Hyatt. 1994. Effects of task language demands and task complexity on computer-mediated groups. Small Group Res. 25(3) 331-366.

Fiedler, F. E. 1966. The effect of leadership and cultural heterogeneity on group performance: A test of the contingency model. $J$. Experiment. Soc. Psych. 2(2) 237-264.

Finholt, T., L. S. Sproull. 1990. Electronic groups at work. Organ. Sci. 1(1) 41-64.

Fulk, J. 1993. Social construction of communication technology. Acad. Management J. 36(5) 921-950.

Galegher, J., R. E. Kraut. 1994. Computer-mediated communication for intellectual teamwork: An experiment in group writing. Inform. Systems Res. 5(2) 110-138.

Geber, B. 1995. Virtual teams. Training. 32(4) 36-42.

Gersick, C. J. G. 1988. Time and transition in work teams: Toward a new model of group development. Acad. Management J. 31(1) $9-41$.

1989. Marking time: Predictable transitions in task groups. Acad. Management J. 32(2) 274-309.

. 1991. Revolutionary change theories: A multi-level exploration 
of the punctuated equilibrium paradigm. Acad. Management Rev. 16(1) 10-36.

- 1994. Pacing strategic change: The case of a new venture. Acad. Management J. 37(1) 9-37.

Giddens, A. 1979. Central Problems in Social Theory. University of California Press, Berkeley, CA.

- 1984. The Constitution of Society. University of California Press, Berkeley, CA.

Ghoshal, S. 1987. Global strategy: An organizing framework. Strategic Management J. 8(3) 425-440.

Hackman, J. R. 1990. Groups That Work (and Those That Don't): Creating Conditions for Effective Teamwork. Jossey-Bass, San Francisco, CA.

Harasim, L. M. 1993. Global Networks: Computers and International Communication. The MIT Press, Cambridge, MA.

Hightower, R., L. Sayeed. 1996. Effects of communication mode and prediscussion information distribution characteristics on information exchange in groups. Inform. Systems Res. 7(4) 451-465.

Hiltz, S. R., K. Johnson, M. Turoff. 1991. Group decision support: The effects of designated human leaders and statistical feedback in computerized conferences. J. Management Inform. Systems $\mathbf{8}(2)$ 81-108.

Hinds, P., S. Kiesler. 1995. Communication across boundaries: Work, structure, and use of communication technologies in a large organization. Organ. Sci. 6(4) 373-393.

Hofstede, G. 1980. Culture's Consequences: International Differences in Work-Related Values. Sage, Newbury Park, CA.

Hollingshead, A. B., J. E. McGrath, K. M. O’Connor. 1993. Group task performance and communication technology. Small Group Res. 24(3) 307-333.

Ives, B., S. L. Jarvenpaa. 1991. Applications of global information technology: Key issues for management. MIS Quart. 15(1) 33 49.

Jarvenpaa, S. L., B. Ives. 1994. The global network organization of the future: Information management opportunities and challenges. $J$. Management Inform. Systems 10(4) 25-57.

— K. Knoll, D. E. Leidner. 1998. Is anybody out there? Antecedents of trust in global virtual teams. J. Management Inform. Systems 14(4) 29-64.

- D. E. Leidner. 1998. Communication and trust in global virtual teams J. Comput. Mediated Comm. 3(4) http://jcmc.mscc. huji.ac.il/vol3/issue4/jarvenpaa.html.

King, N. 1998. Template analysis. G. Symon, C. Cassell, eds. Qualitative Methods and Analysis in Organizational Research: A Practical Guide. Sage, Thousand Oaks, CA. 118-134.

Kirchmeyer, C., A. Cohen. 1992. Multicultural groups: Their performance and reactions with constructive conflict. Group and Organ. Management 17(2) 153-170.

Kobrin, S. 1991. An empirical analysis of the determinants of global integration. Strategic Management J. 12(Special) 17-31.

Kogut, B. 1985. Designing global strategies: Comparative and competitive value-added chains. Sloan Management Rev. 26(4) 1528.

Kristof, A. L., K. G. Brown, H. P. Sims, Jr., K. A. Smith. 1995. The virtual team: A case study and inductive model. M. M. Beyerlein, D. A. Johnson, S. T. Beyerlein, eds. Advances in Interdisciplinary
Studies of Work Teams: Knowledge Work in Teams Vol. 2. JAI Press, Greenwich, CT, 229-253.

Lawrence, P., J. Lorsch. 1967. Organization and Environment. Harvard Business School Press, Boston, MA.

Lea, M., T. O'Shea, P. Fung. 1995. Constructing the networked organization: Content and context in the development of electronic communications. Organ. Sci. 6(4) 462-478.

Lee, A. S. 1994. Electronic mail as a medium for rich communication: An empirical investigation using hermeneutic interpretation. MIS Quart. 18(2) 143-157.

Lind, M. R., R. W. Zmud. 1995. Improving interorganizational effectiveness through voice mail facilitation of peer-to-peer relationships. Organ. Sci. 6(4) 445-461.

Ling, S. C. 1990. The effects of group cultural composition and cultural attitudes on performance. Unpublished doctoral dissertation, University of Western Ontario, London, Canada.

Lipnack, J., J. Stamps. 1997. Virtual Teams-Reaching Across Space, Time, and Organizations with Technology. John Wiley \& Sons, New York.

Markus, M. L. 1994. Electronic mail as the medium of managerial choice. Organ. Sci. 5(4) 502-527.

Maznevski, M. L. 1994a. Synergy and performance in multicultural teams. Unpublished doctoral dissertation, University of Western Ontario, London, Canada.

_ 1994b. Understanding our differences: Performance in decisionmaking groups with diverse members. Human Relations 47(5) 531-552.

Maznevski, M. L., J. J. DiStefano. 1995. The mortar in the mosaic: A new look at process and performance in decision-making teams. Unpublished doctoral dissertation, Richard Ivey School of Business, University of Western Ontario, London, Canada.

,-- , Carolina B. Gomez, Niels G. Noorderhaven, Peichuan Wu. 1997. The cultural orientations framework and international management research. Presented at the Academy of International Business Annual Meeting, Monterrey, MX.

McGrath, J. E. 1984. Groups: Interaction and Performance. PrenticeHall, Englewood Cliffs, NJ.

McLeod, P. L., S. A. Lobel. 1992. The effects of ethnic diversity on idea generation in small groups. Best Papers Proceedings, Academy of Management Annual Meeting, Las Vegas, NV, 227-231.

Melymuka, K. 1997a. Tips for teams. Computerworld 31(17) 72.

—. 1997b. Virtual realities. Computerworld 31(17) 70-72.

Merrick, N. 1996. Remote control. People Management 2(19) 40-41.

Miles, M. B., A. M. Huberman. 1994. Qualitative Data Analysis: An Expanded Sourcebook, 2nd ed. Sage, Thousand Oaks, CA.

Mintzberg, H. 1989. Organizational design: Fashion or fit? Harvard Bus. Rev. 59(1) 103-115.

Ngwenyama, O. K., A. S. Lee. 1997. Communication richness in electronic mail: Critical social theory and the contextuality of meaning. MIS Quart. 21(2) 145-167.

Ocker, R., J. Fjermestad, S. R. Hiltz, K. Johnson. 1998. Effects of four modes of group communication on the outcomes of software requirements determination. J. Management Inform. Systems 15(1) 99-118.

— S. R. Hiltz, M. Turoff, J. Fjermestad. 1995-1996. The effects of distributed group support and process structuring on software requirements development teams: Results on creativity and quality. J. Management Inform. Systems 12(3) 127-153. 
O’Connor, K. M., D. H. Gruenfeld, J. E. McGrath. 1993. The experience and effects of conflict in continuing work groups. Small Group Res. 24(3) 362-382.

O’Hara-Devereaux, M., R. Johansen. 1994. Global Work. Jossey-Bass Publishers, San Francisco, CA.

Orlikowski, W. J., J. Yates. 1994. Genre repertoire: The structuring of communicative practices in organizations. Admin. Sci. Quart. 39(4) 541-574.

,,-- K. Okamura, M. Fujimoto. 1995. Shaping electronic communication: The metastructuring of technology in the context of use. Organ. Sci. 6(4) 423-444.

Pickering, J. M., J. L. King. 1995. Constructing the networked organization: Content and context in the development of electronic communications. Organ. Sci. 6(4) 479-486.

Rice, R. E. 1992. Task analyzability, use of new media, and effectiveness: A multi-site exploration of media richness. Organ. Sci. 3(4) 475-500.

Saunders, C., J. W. Jones. 1990. Temporal sequences in information acquisition for decision making. Acad. Management Rev. 15(1) 29-46.

Schatz, B. R. 1991-1992. Building an electronic community system. J. Management Inform. Systems 8(3) 87-107.

Schein, E. H. 1984. Coming to a new awareness of organizational culture. Sloan Management Rev. 25(2) 3-16.

Schmitz, J., J. Fulk. 1991. Organizational colleagues, media richness, and electronic mail. Comm. Res. 18(4) 487-523.

Smith, J. Y., M. T. Vanecek. 1990. Dispersed group decision making using nonsimultaneous computer conferencing: A report of research. J. Management Inform. Systems 7(2) 71-92.

Spears, R., M. Lea. 1994. Panacea or panopticon? The hidden power in computer-mediated communication. Comm. Res. 21(4) 427459.

Straub, D. 1994. The effect of culture on IT diffusion: E-mail and fax in Japan and the U.S. Inform. Systems Res. 5(1) 23-47.

— E. Karahanna. 1998. Knowledge worker communications and recipient availability: Toward a task closure explanation of media choice. Organ. Sci. 9(2) 160-175.

Straus, S. G. 1996. Getting a clue: The effects of communication media and information distribution on participation and performance in computer-mediated and face-to-face groups. Small Group Res. 27(1) 115-142.

Strauss, A., J. Corbin. 1990. Basics of Qualitative Research: Grounded Theory Procedures and Techniques. Sage, Newbury Park, CA.

Thompson, J. D. 1967. Organizations in Action. McGraw-Hill, New York.

Accepted by Daniel Robey; received May 19, 1999.
Townsend, A. M., S. M. DeMarie, A. R. Hendrickson. 1996. Are you ready for virtual teams? HRMagazine 41(9) 122-126.

Trevino, L. K., J. Webster. 1992. Flow in computer-mediated communication. Comm. Res. 19(5) 539-573.

Turoff, M., S. R. Hiltz, A. N. F. Bahgat, A. R. Rana. 1993. Distributed group support systems. MIS Quart. 17(4) 399-417.

Valacich, J. S., J. F. George, J. F. Nunamaker, D. R. Vogel. 1994. Physical proximity effects on computer-mediated group idea generation. Small Group Res. 25(1) 83-104.

_ D. Paranka, J. F. George, J. F. Nunamaker, Jr. 1993. Communication concurrency and the new media. Comm. Res. 20(2) 249276.

Walther, J. B. 1992. Interpersonal effects in computer-mediated interaction. Comm. Res. 19(1) 52-90.

. 1995. Relational aspects of computer-mediated communication: Experimental observations over time. Organ. Sci. 6(2) 186-203. . 1996. Computer-mediated communication: Impersonal, interpersonal and hyperpersonal interaction. Comm. Res. 23(1) 3-43.

_ J. F. Anderson, D. W. Park. 1994. Interpersonal effects in computer-mediated interaction. Comm. Res. 21(4) 460-487.

Watson, W. E., K. Kumar, L. K. Michaelsen. 1993. Cultural diversity's impact on interaction process and performance: Comparing homogeneous and diverse task groups. Acad. Management J. 36(3) 590-602.

Webster, J. 1998. Desktop videoconferencing: Experiences of complete users, wary users, and non-users. MIS Quart. 22(3) 257-286.

Weisband, S. P., S. K. Schneider, T. Connolly. 1995. Computer-mediated communication and social information: Status salience and status differences. Acad. Management J. 38(4) 1124-1151.

Yates, J., W. J. Orlikowski. 1992. Genres of organizational communication: A structurational approach to studying communication and media. Acad. Management Rev. 17(2) 299-326.

Yin, R. K. 1989. Case Study Research: Design and Methods, rev. ed. Sage, Newbury Park, CA.

Young, R. 1998. The wide-awake club. People Management 4(3) 4649.

Zack, M. H. 1993. Interactivity and communication mode choice in ongoing management groups. Inform. Systems Res. 4(3) 207-239.

_ J. L. McKenney. 1995. Social context and interaction in ongoing computer-supported management groups. Organ. Sci. 6(4) 394422.

Zander, L. 1997. The license to lead: An 18 country study of the relationship between employees' preferences regarding interpersonal leadership and national culture. Stockholm: Institute of International Business, Stockholm School of Economics. 